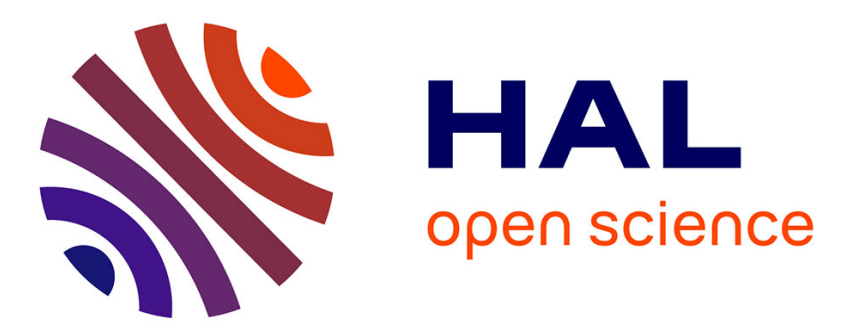

\title{
A case study of wave motion above a jet stream flow system observed by an instrumented balloon Jean Barat, Charles Cot
}

\section{To cite this version:}

Jean Barat, Charles Cot. A case study of wave motion above a jet stream flow system observed by an instrumented balloon. Tellus A, 1984, 36A, pp.480 - 489. 10.3402/tellusa.v36i5.11648 . insu03580971

\section{HAL Id: insu-03580971 https://hal-insu.archives-ouvertes.fr/insu-03580971}

Submitted on 18 Feb 2022

HAL is a multi-disciplinary open access archive for the deposit and dissemination of scientific research documents, whether they are published or not. The documents may come from teaching and research institutions in France or abroad, or from public or private research centers.
L'archive ouverte pluridisciplinaire HAL, est destinée au dépôt et à la diffusion de documents scientifiques de niveau recherche, publiés ou non, émanant des établissements d'enseignement et de recherche français ou étrangers, des laboratoires publics ou privés. 


\section{A case study of wave motion above a jet stream flow system observed by an instrumented balloon}

\section{Jean Barat \& Charles Cot}

To cite this article: Jean Barat \& Charles Cot (1984) A case study of wave motion above a jet stream flow system observed by an instrumented balloon, Tellus A: Dynamic Meteorology and Oceanography, 36:5, 480-489, DOI: 10.3402/tellusa.v36i5.11648

To link to this article: https://doi.org/10.3402/tellusa.v36i5.11648

$$
\begin{aligned}
& \text { (c) } 1984 \text { The Author(s). Published by Taylor \& } \\
& \text { Francis. }
\end{aligned}
$$

\section{曲 Published online: 15 Dec 2016.}

Submit your article to this journal $\pi$

Џ Article views: 113 


\title{
A case study of wave motion above a jet stream flow system observed by an instrumented balloon
}

\author{
By JEAN BARAT," Université Paris VI, France and CHARLES COT, Service d'Aéronomie du CNRS, \\ B.P. 3, 91370 Verrieres le Buisson, France
}

(Manuscript received July 1, 1983; in final form February 21, 1984)

\begin{abstract}
An analysis is presented of the data obtained from an instrumented balloon rising through a jet stream. Emphasis is placed on the determination of the vertical atmospheric velocity. The analysis of the temperature and velocity perturbations shows evidence of a wave structure propagating upward. An estimation of the vertical flux of horizontal momentum is given. These preliminary results show clearly the ability of our helisonde to measure wave motions with a vertical velocity as low as $0.1 \mathrm{~m} \mathrm{~s}^{-1}$. The method allows a direct measurement of wave propagation in the stratosphere.
\end{abstract}

\section{Introduction}

Gravity waves are commonly observed in the atmosphere and their importance has been emphasized during the last decade. They can interact with the mean flow (viscous dissipation, Newtonian cooling, critical level, shear instability) and cause velocity changes. Lindzen (1982), Holton (1982) and Matsuno (1982) have proposed such interaction mechanisms to explain the mean circulation of the middle atmosphere.

The experimental study of atmospheric waves can be carried out by using instrumented aircraft (Lilly and Kennedy, 1973), UHF-VHF radars (Rüster et al., 1978), LIDAR (Chanin and Hauchecorne, 1981) or constant level balloons (Massman, 1981). The ability of these methods to obtain measurements in the middle stratosphere is nevertheless limited to large amplitude waves and the observations remain sparse in the 20-35 km altitude range.

Most of the gravity wave sources are in the troposphere and they can be related to orography, to the jet stream (Bertin et al., 1977) or to convective storms (Uccellini, 1975). As they

\footnotetext{
- Present address: Service d'Aéronomie du CNRS BP 3, 91370 Verrieres le Buisson, France.
}

propagate, these waves are capable of exchanging momentum. In order to explore their interaction with the background flow, it is then worthwhile to perform continuous vertical measurements over a broad range of altitudes from the troposphere up to the middle stratosphere.

Lalas and Einaudi (1980) have shown that gravity waves can be detected through the induced vertical variation of the ascent rate of rawinsonde balloons. However, even in the case of constant volume balloons, the relative ascent velocity changes cannot be computed with great accuracy and the method can only be used when the wave motion has large amplitude. During the last few years, we have devised a new balloon-borne instrument, the helisonde, to study gravity waves between 0 and 30 km (Barat and Génje, 1982). The sounding provides, without assumptions about the vertical velocity of the balloon, continuous profiles of temperature, pressure and vertical velocity of the air. With this set of parameters, it is possible to identify wave motions and to calculate some of their characteristics. In this paper, we present typical results obtained during a test flight of the helisonde. A gravity wave motion is observed from above the tropopause up to $26 \mathrm{~km}$. The measurement technique is discussed in the following section. The data set is presented in Section 3 and the analysis is developed in Sections 4 and 5. 


\section{Measurement technique}

\subsection{The helisonde}

The instrumentation has been described in detail in Barat and Génie (1982) and we include here only the main characteristics of the measurement technique. The helisonde is hung at a distance $h=$ $160 \mathrm{~m}$ below a zero pressure balloon. During the ascent, an ionic anemometer, located ahead of the helisonde, measures the relative vertical velocity $W_{R}$ of the gondola with respect to the air. The detection limit of the anemometer, through the telemetry system, is $1 \mathrm{~cm} \mathrm{~s}^{-1}$. The zero error $\delta W_{R}$ is due to mechanical constraints, and varies slowly with altitude but remains always below $0.3 \mathrm{~m} \mathrm{~s}^{-1}$. The pressure $P$ is sampled every $0.125 \mathrm{~s}$ by a metallic capsule. The resolution is limited by the telemetry system which introduces a digitization step $\delta P$ of $0.06 \mathrm{mb}$. Two identical microbead thermistors measure the temperature $T$ of the ambient atmosphere every 0.0313 s. The time response $t$ of the sensors lies between $s \mathrm{~s}(1000 \mathrm{mb})$ and $19 \mathrm{~s}(25 \mathrm{mb})$ and the resolution $\delta T$ through the telemetry device is of $0.03 \mathrm{~K}$.

\subsection{The vertical velocity measurement}

Assuming that the atmosphere is in a hydrostatic equilibrium, the vertical velocity $W_{A}$ of the air is given by

$W_{A}=W_{P}-W_{R}$

where

$W_{P}=-\frac{1}{\rho g} \frac{\mathrm{d} P}{\mathrm{~d} t}$

is the vertical velocity of the balloon. To calculate $W_{p}$ from eq. (2), the uniform series of pressure $P(n)$ cannot be used directly because the digitization step $\delta P$ is of the same order of magnitude as the actual pressure variation $|P(n)-P(n+1)|$. We have therefore filtered $P(n)$ by a running triangular window $f(n)$ defined by

$$
\begin{aligned}
& f(n)=1-\frac{|2 n|}{N+1} \\
& \text { for } \quad-\frac{1}{2}(N-1) \leqslant n \leqslant \frac{t}{2}(N-1),
\end{aligned}
$$

where $N=383$. We have calculated $W_{A}$ in eq. (1) by using the filtered value

$$
W_{P}^{f}(n)=-\frac{1}{\rho g} f \frac{\mathrm{d}[f P]}{\mathrm{d} t}
$$

From eq. (4), we have obtained a uniform altitude series of $W_{p}^{\prime}$ every $5 \mathrm{~m}$ along the vertical. Due to the filtering, all the variations of $W_{p}^{f}$ with vertical scale lower than the filter length $\lambda_{c}=$ $0.5 N \bar{W}_{p}, \Delta t=130,(\Delta t$ is the time sampling interval $=0.125 \mathrm{~s}$ ) are attenuated. As we will see later, this is of little importance for our observations. After the data processing, the accuracy of the $W_{p}^{\prime}$ values which depend on the calibration factor and on the filtering, is about $3 \mathrm{~cm} \mathrm{~s}^{-1}$.

While the uncertainty of the $W_{p}^{f}$ measurement depends on the resolution of the pressure sensor, the $W_{R}$ measurement is essentially perturbed by the pendular motion of the helisonde with a period of about $12 \mathrm{~s}$ (Barat and Génie, 1982). To suppress this effect, we have applied the filter $f$ to the time series of $W_{R}$. The residual error is less than $3 \mathrm{~cm}$ $s^{-1}$. The uncertainty of $W_{R}$ also depends on the calibration of the anemometer and is below $10 \%$. The atmospheric vertical velocity is then calculated by

$W_{A}^{f}=W_{P}^{\prime}-W_{R}^{f}$.

The zero error $\delta W_{R}$ has been estimated by assuming that in the stratosphere, over the 14-28 $\mathrm{km}$ altitude range, the mean value of $W_{A}$ is 0 :

$\int_{14.000}^{28,000}\left(W_{P}^{f}-W_{R}^{\prime}-\delta W_{R}\right) d z^{\prime}=0$.

We have found $\delta W_{R}=0.15 \mathrm{~m} \mathrm{~s}^{-1}$ while the value measured in the laboratory before the flight was $0.3 \mathrm{~m} \mathrm{~s}^{-1}$.

In summary, the helisonde enables us to detect after data processing wave motions of vertical wavelengths one order of magnitude above $\lambda_{\mathrm{c}}=$ $130 \mathrm{~m}$ with a resolution below $10 \mathrm{~cm} \mathrm{~s}^{-1}$. This accuracy is substantially better than that obtained with instrumented aircraft, especially in the stratosphere.

\subsection{The horizontal wind measurement}

During the sounding, the helisonde measured the wind shear $\mathrm{d} \vec{V} / \mathrm{d} z$ between the balloon and the gondola. By integration, it is possible to obtain the wind profile $\vec{V}(z)$ during the sounding (Barat and Génie, 1982). The accuracy of this measurement 
depends on the behaviour of the ballon as a wind sensor and we have shown that, in the case of small balloons moving slowly along the vertical, we can have strong confidence in the method (Barat, 1982). During the test flight detailed here, a 87,000 $\mathrm{m}^{3}$ balloon was used. With an ascent velocity of about $5.5 \mathrm{~m} \mathrm{~s}^{-1}$, the time response of the balloon to small horizontal scale wind perturbation was about $20 \mathrm{~s}$, hence the measurement of $\mathrm{d} \vec{V} / \mathrm{dz}$ may be significantly erroneous. As explained in Section 5 , we have only used this part of the measurement to derive the propagation direction of the wave.

\section{The data set}

\subsection{The flight}

A test flight was performed on October 15, 1980 at the French Balloon Facility Base of the Centre National d'Etudes Spatiales (CNES) at Aire sur

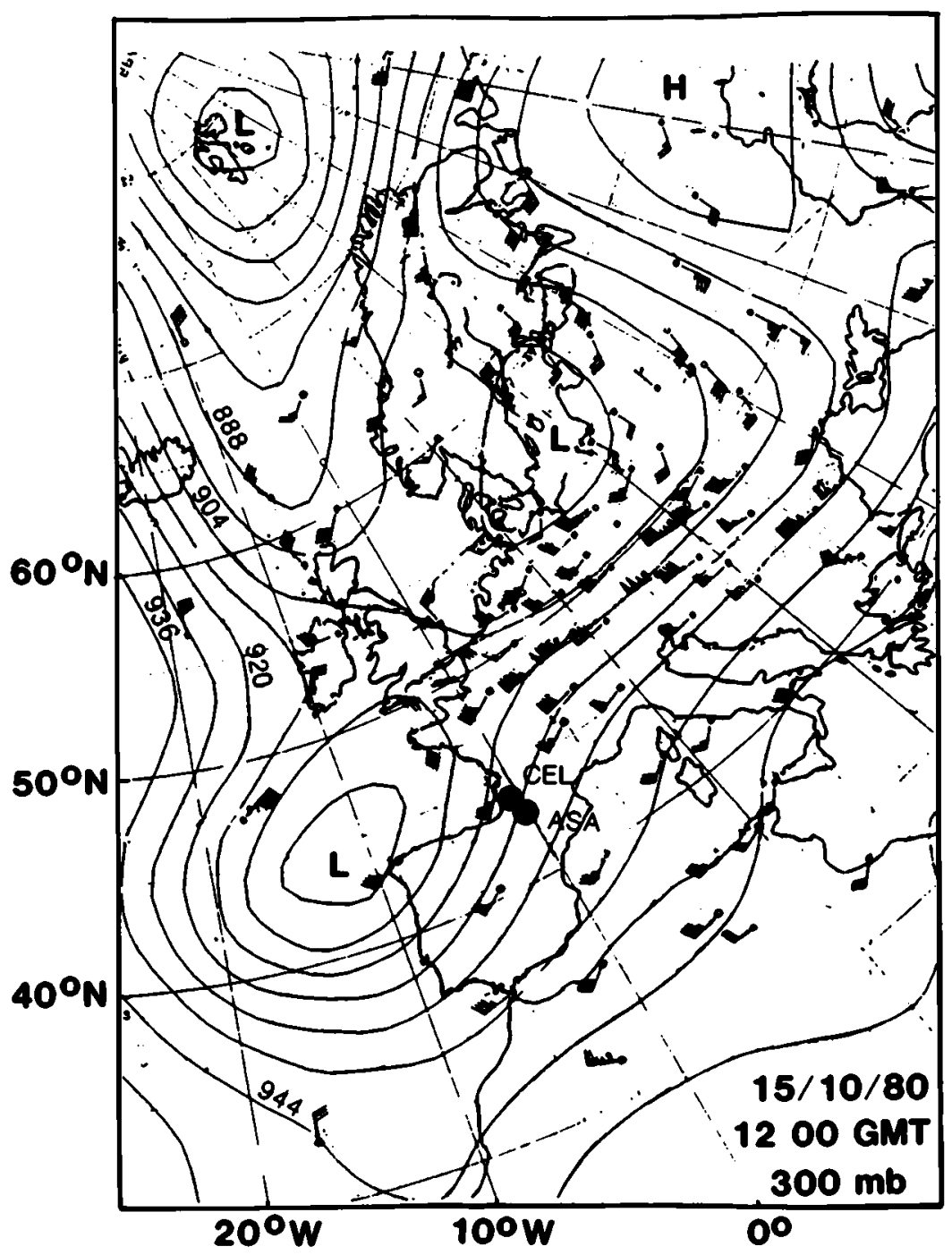

Fig. 1. Analysis $300 \mathrm{mb} 1200 \mathrm{GMT}$ October 15, 1980. The balloon launching site (ASA), and Centre d'Essais des Landes (CEL) are indicated. 
l'Adour (ASA), France. The balloon, launched at 13.45 GMT reached its nominal float level $(35 \mathrm{~km})$ at 15.47 GMT. Due to a mechanical failure in the helisonde, no data was obtained above $28 \mathrm{~km}$. During the flight, a cyclone at the surface level was centered at $\left(10^{\circ} \mathrm{E}, 45^{\circ} \mathrm{N}\right)$. It was also present higher up in the atmosphere. The $\mathbf{3 0 0} \mathrm{mb}$ chart at $12.00 \mathrm{GMT}$ is shown in Fig. I. We have also plotted the geographic positions of the launching site and that of the Centre d'Essais des Landes (CEL) where a wind measurement was performed at 12.44 GMT just before the flight. A SW-NE jet
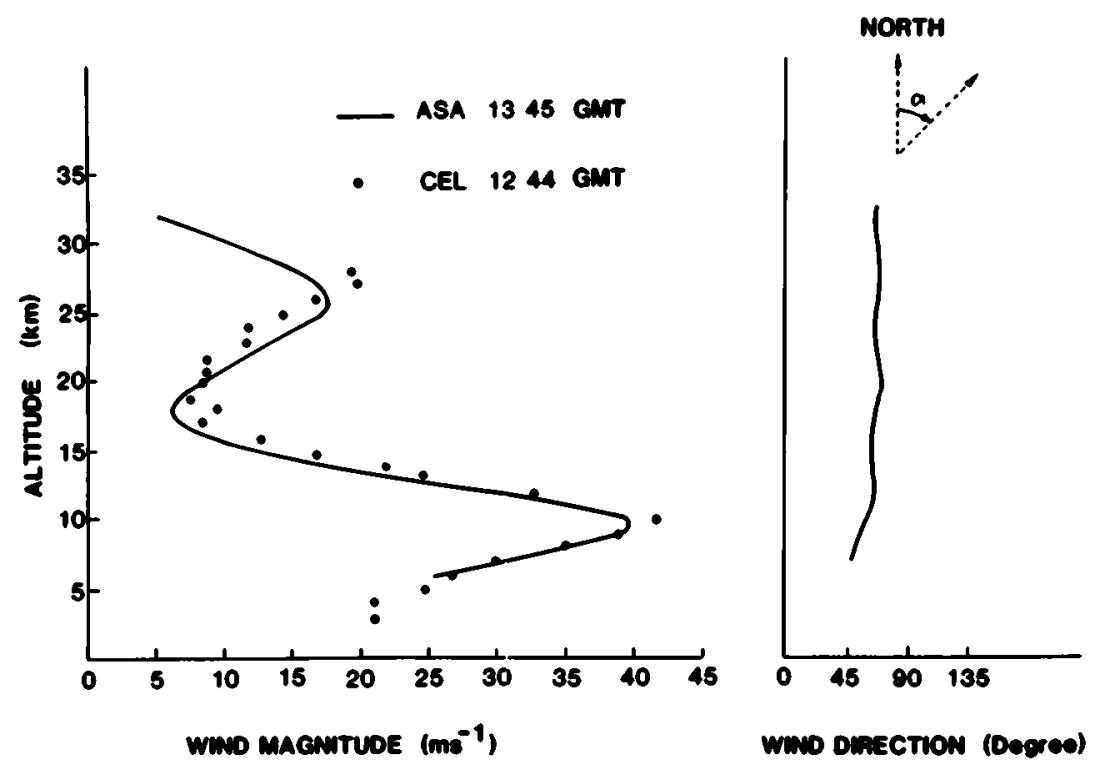

Fig. 2. Magnitude and direction of the wind measured from the tracking system of the balloon (solid line). The dots correspond to the CEL wind measurements.
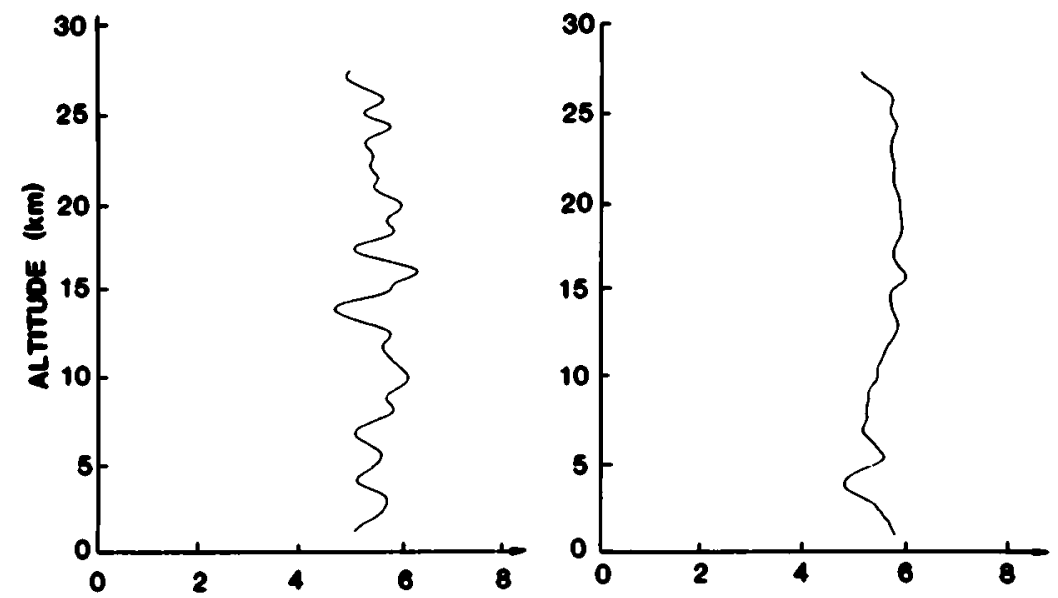

ABSOLUTE VERTICAL VELOCITY (me-1) AELATIVE VERTICAL VELOCITY $\left(m e^{-1}\right.$ )

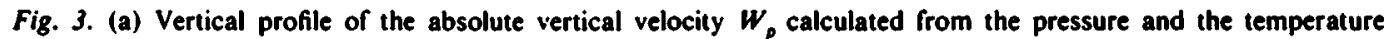
measurements. (b) Vertical profite of the relative vertical velocity $W_{n}$ measured with the ionic anemometer.

Tellus 36A (1984), 5 
stream was present over the launching site and the tropopause level was at $11 \mathrm{~km}$. During the ascent, the balloon was tracked by a $400 \mathrm{MHz}$ telemetry system and in Fig. 2 the wind profile between 3 and $32 \mathrm{~km}$ is shown. We have also plotted the values obtained at CEL. We note a secondary maximum of the wind around $26 \mathrm{~km}$ and a remarkably constant direction for the mean flow.

\subsection{Experimental results}

Fig. 3a shows the profile of the velocity $W_{p}^{f}$. A wave-like structure with an amplitude of about 0.4 $\mathrm{m} \mathrm{s}^{-1}$ is seen in the stratosphere. Its vertical wavelength is approximately $1.6 \mathrm{~km}$. This variation could be due to a non-constant ascent rate of the balloon. However, the profile of the relative velocity $W_{R}^{\prime}$ in Fig. $3 b$ shows practically no corresponding fluctuations. Thus the measurements present evidence of vertical air motions.

Fig. 4a presents the vertical velocity profile $W_{\hat{A}}^{\prime}$ computed from eq. (5). The wave-like structure is predominant in the stratosphere, while in the troposphere it is superimposed on a large-scale vertical structure. Fig. $\mathbf{4 b}$ shows the temperature profile obtained by averaging the two temperature measurements. Large-amplitude fluctuations can be seen above the tropopause. Because of the strong mean temperature gradient, they are not clearly visible within the troposphere.

\section{Evidence of a wave structure}

\subsection{Perturbation profiles}

The observations of atmospheric wave motions are often complicated by the presence of multiple wave modes. In our case, the vertical profile of $W_{A}^{f}$ in the stratosphere provides evidence of a wave structure with a well-defined wavelength. In order to separate the wave-induced velocity from the background, we have filtered the altitude series $\boldsymbol{W}_{\boldsymbol{A}}^{\prime}$ with a running window $F, I \mathrm{~m}$ long. We then define a perturbation velocity profile

$W^{\prime}=\left(1-F_{1}\right) W_{A}^{\prime}$.

In the calculations, we have used $l=1600 \mathrm{~m}$ and $l=3200 \mathrm{~m}$. The results are compared in subsection 4.2. Since the mean vertical velocity in the stratosphere is small, the filtering cannot alter the $W^{\prime}$ profile, especially in the case of a nondispersive wave. In the troposphere, however, large-scale structures (convective motions) can affect the results and, in particular, the important property $\bar{W}^{\prime}=0$ over a wavelength may not be preserved.

We have applied the same filter $F$ to the temperature profile and we obtain

$T^{\prime}=\left(1-F_{1}\right) T$.

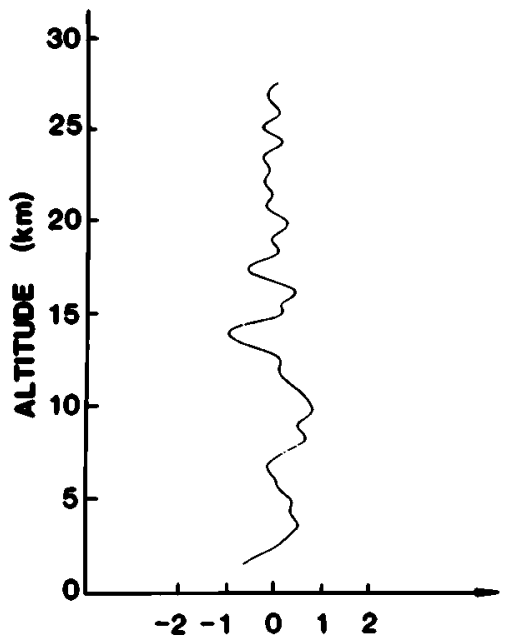

ATMOSPHERIC VELOCITY $\left(\mathrm{ms}^{-1}\right)$

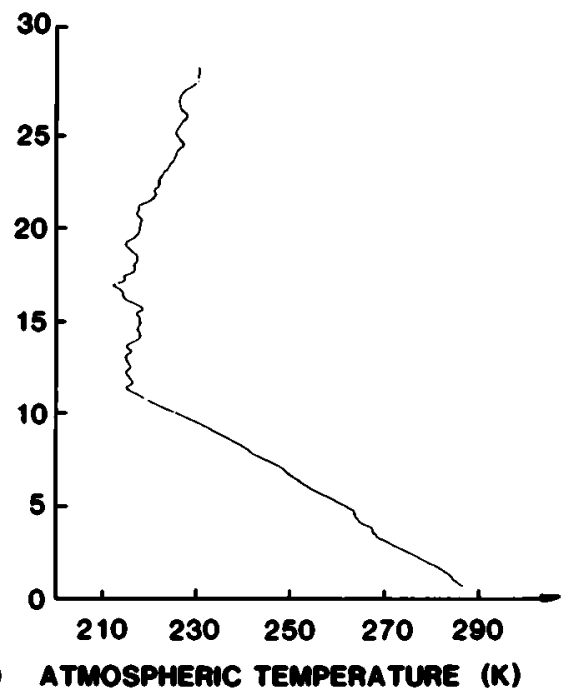

ATMOSPHEAIC TEMPERATURE (K)

Fig. 4. (a) Vertical profile of the atmospheric velocity $W_{A}$. Note the large amplitude variations around the tropopause level. (b) Temperature profile measured along the sounding. 

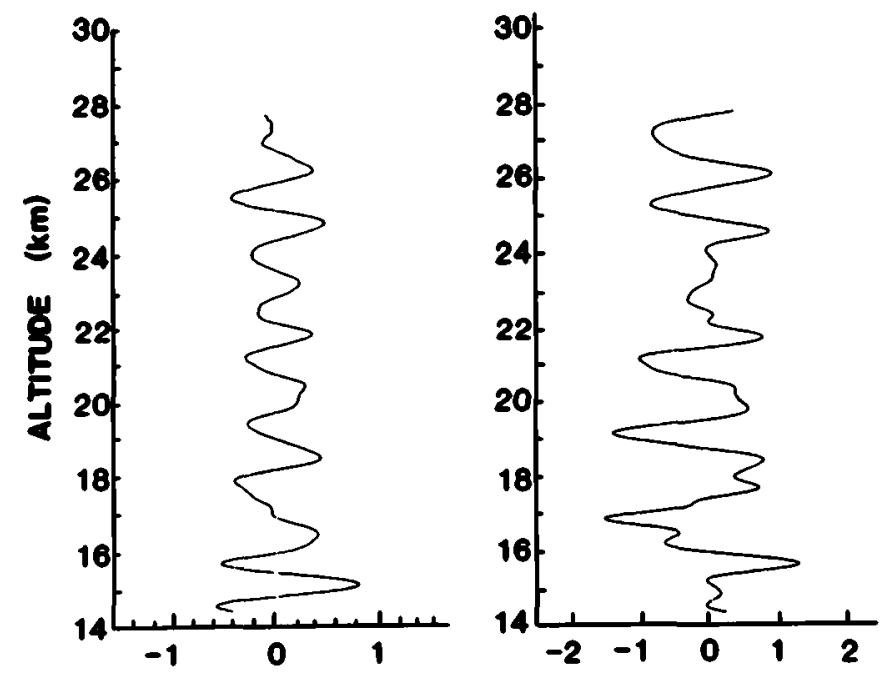

VELOCITY PERTUABATION (ms-1) TEMPERATURE PERTUABATION (K)

Fig. 5. (a) Vertical velocity $W^{\prime}$ and (b) temperature perturbation $T^{\prime}$ induced by the wave motion. Note the similar behaviour (amplitude and wavelength).

Errors in the temperature perturbation $T^{\prime}$ may result from the large mean tropospheric gradient. Moreover, the temperature measurement may be biased within a cloudy atmosphere and the overall error is difficult to estimate.

From the above discussion, we conclude that only the stratospheric measurements can be used directly and we present in Figs. $5 \mathrm{a}$ and $5 \mathrm{~b}$ the two perturbation profiles, $W^{\prime}$ and $T^{\prime}$, computed with $l=1600 \mathrm{~m}$ above $14 \mathrm{~km}$. They appear to be quite well correlated, except around $22 \mathrm{~km}$.

\subsection{Phase and correlation of the temperature and vertical velocity}

The propagation of a gravity wave induces a relationship between velocity and temperature fluctuations. It is characterized by the correlation function

$R(d)=\frac{\left\langle W^{\prime}(z) T^{\prime}(z+d)\right\rangle}{\left\langle W^{\prime 2}(z) T^{\prime 2}(z+d)\right\rangle^{1 / 2}}$,

where $d$ is the lag distance. The maximum $R\left(d_{m}\right)$ of $R(d)$ gives the correlation coefficient of $W^{\prime}$ and $T^{\prime}$, and at the distance $d_{m}$ the phase angle is given by

$\Delta \Phi_{r^{\prime}, w^{\prime}}=2 \pi \frac{d_{m}}{\lambda_{m}}$ where $\lambda_{m}$, the local wavelength, is the distance between two extrema.

As a typical example, we show in Fig. 6 the function $R(d)$ averaged over a vertical interval, 2 $\mathrm{km}$ long, centred at $25.1 \mathrm{~km}$ for both $l=1600 \mathrm{~m}$ and $l=3200 \mathrm{~m}$. We observe practically the same variation. In fact the measured phase angle must be corrected by the instrumental phase lag $\delta \Phi$ related to the time response $\tau$ of the temperature sensor by

$\delta \Phi=2 \pi \frac{W_{0} \tau}{\lambda_{m}}$.

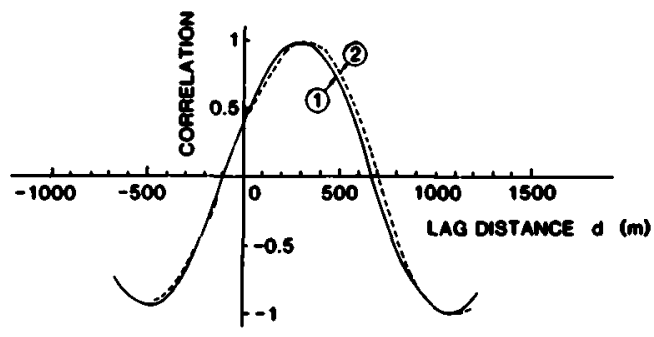

Fig. 6. Cross correlation function of $W^{\prime}$ and $T^{\prime}$ at 25.1 $\mathrm{km}$. The curve labelled (1) corresponds to a filtering over $1600 \mathrm{~m}$ while the curve labelled (2) corresponds to a filtering over $3200 \mathrm{~m}$. The correlation coefficient is 0.98 and the phase angular difference before correction (see text) is $-70^{\circ}$. 
Table 1. Phase and coherence of the wave motion

\begin{tabular}{lll}
\hline Altitude $(\mathrm{km})$ & Correlation coefficient & $\begin{array}{l}\text { Actual phase } \\
\text { angle }\end{array}$ \\
\hline 26.1 & 0.88 & -84 \\
25.6 & 0.95 & -87 \\
25.1 & 0.98 & -85 \\
24.6 & 1 & -96 \\
24.1 & 0.85 & -90 \\
23.6 & very small & not measurable \\
23.1 & very small & not measurable \\
22.6 & 0.8 & +50 \\
22.1 & 0.65 & -45 \\
21.6 & 0.85 & -50 \\
21.1 & 0.90 & -62 \\
20.6 & 0.95 & -60 \\
20.1 & 0.93 & -70 \\
19.6 & 0.92 & -80 \\
19.1 & 0.95 & -91 \\
\hline
\end{tabular}

In Table 1 we give the actual phase angle $\left(\Delta \Phi_{T^{\prime}, W^{\prime}}+\delta \phi\right)$ and the correlation coefficient measured above $19 \mathrm{~km}$ over 13 overlapping intervals of $2 \mathrm{~km}$ length. The high correlation between $T^{\prime}$ and $W^{\prime}$ and the constancy of the actual phase angle allow us to conclude that a wave motion system was present during the sounding.

\section{Characteristics of the wave motion}

When the frequency $\omega$ of the wave is much above the inertial frequency, the polarization can be neglected if the atmosphere is taken to be stationary in the absence of waves. Along the direction $x$ of propagation, the vertical velocity and the temperature fluctuation can be derived from the stream function $\psi$,

$\psi=A \mathrm{e}^{\left(\left(K_{x x}+K_{z 2}-\omega\right)\right.}$,

$W^{\prime}=\operatorname{Re}\left(-\frac{d \psi}{d x}\right)=A K_{x} \sin \left(K_{x} x+K_{z} z-\omega t\right)$,

$T^{\prime}=-\frac{A K_{x}}{\omega}\left(\Gamma_{1}+\frac{\partial \bar{T}}{\partial z}\right) \cos \left(K_{x} x+K_{z} z-\omega t\right)$,

where $K_{x}$ and $K_{z}$ are the horizontal and vertical wavenumbers respectively, $\Gamma_{\text {a }}$ the adiabatic lapse rate and $A$ an amplitude. From eqs. (7) and (8), it follows that $T^{\prime}$ is $+90^{\circ}$ out of phase with $W^{\prime}$.

\subsection{Direction of propagation}

As explained in Section 3, the balloon used for the test flight could not be assumed a perfect wind sensor for the induced horizontal wave velocity $U^{\prime}$. From eq. (6) we have

$U^{\prime}=\operatorname{Re}(\mathrm{d} \psi / \mathrm{d} z)=-A K_{z} \sin \left(K_{x} x+K_{z} z-\omega t\right)$.

Fig. 7 presents the wind intensity profile computed from

$$
\vec{V}(z)=\int_{14,000}^{z}\left(\mathrm{~d} \vec{V} / \mathrm{d} z^{\prime}\right) \mathrm{d} z^{\prime}+\vec{C}
$$

The altitude independent constant $\vec{C}$ has been adjusted so that $\vec{V}(z)$ equals the wind $\vec{V}_{1}(z)$ measured at $19,000 \mathrm{~m}$ by the balloon tracking system. We have also plotted $V_{1}(z)$ in Fig. 7 and we note the similar behaviour of the two variations. Over the $14,000 \mathrm{~m}$ altitude range, the integrated difference between the two measurements remains below $5 \mathrm{~m} \mathrm{~s}^{-1}$. This leads to an uncertainty

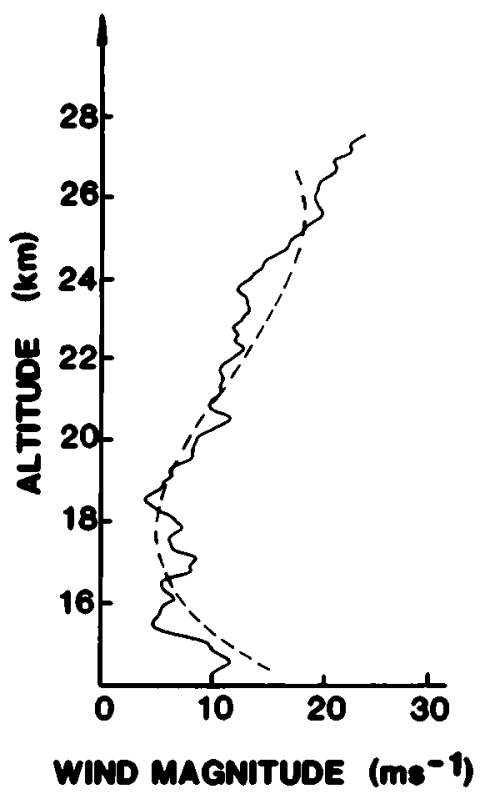

Fig. 7. Comparison between the wind magnitude profile measured directly by the tracking system (dashed line) and by the helisonde measurement (solid line). Note the slight difference over the $14,000 \mathrm{~m}$ altitude range. 
$\delta(d V / d z)$ of about $4 \cdot 10^{-4} s^{-1}$. From eq. (16) we can calculate the horizontal wind fluctuations along one direction $a$ and along the direction perpendicular to it:

$U_{a}^{\prime}=\left(1-F_{1600}\right) V_{n}$,

$U_{1 n}^{\prime}=\left(1-F_{1600}\right) V_{1 a}$,

where $V_{a}$ and $V_{1 a}$ are the components along the two directions. The ratio

$$
R(\alpha)=\frac{\left\langle V_{n}^{2}\right\rangle}{\left\langle V_{1 n}^{2}\right\rangle},
$$

where the average is taken over the $14,000-28,000$ $m$ altitude range, is then a polarization factor and must be maximal along the direction of propagation. Fig. 8 presents the variation of $R(\alpha)$. Clearly we observe a maximum of $R=2.1$ around $a_{0}=60^{\circ}$, i.e. along the jet stream flow, so that a wave propagates in this direction. However, the ratio $R\left(a_{0}\right)$ is small and suggests an important background noise. This can be related to the

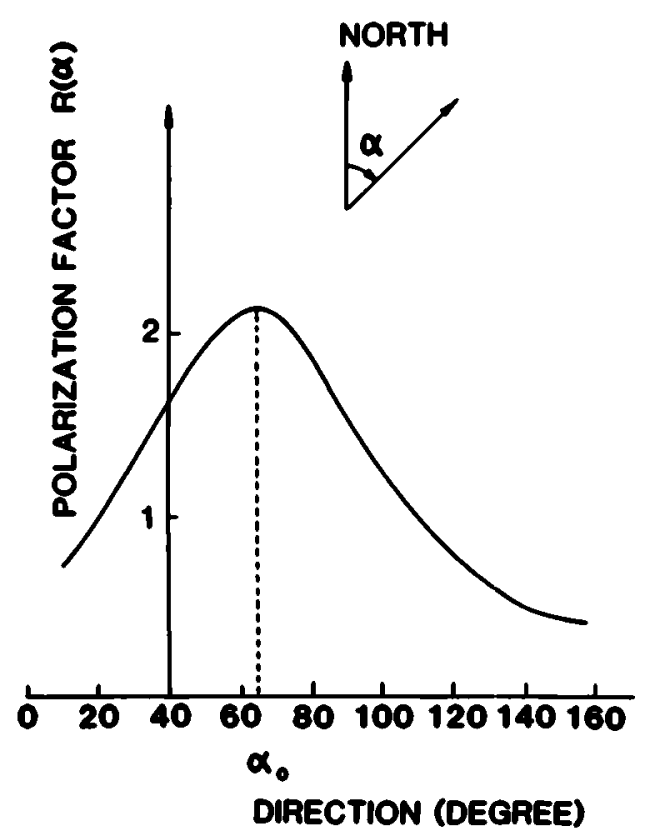

Fig. 8. Angular variation of the polarization factor $\boldsymbol{R}(\alpha)$ (see text). The value $\alpha$ where $R(\alpha)$ is maximal corresponds to the direction of propagation of the wave, i.e. along the jet stream. balloon behaviour and explains why we have not found a significant phase correlation between $U^{\prime}$ and $W^{\prime}$. The result also gives evidence that the perturbation $U^{\prime}$ is small.

The results in Table 1 show that, except near $22 \mathrm{~km}$ where the perturbation amplitudes are very small, $W^{\prime}$ is generally $+90^{\circ}$ out of phase with $T^{\prime}$. Hence the vertical phase velocity, negative with respect to the direction of the balloon motion, is downward.

\subsection{Intrinsic frequency}

Using eqs. (13) and (14), the intrinsic frequency $\omega$ can be derived from

$\omega=\frac{W_{\max }^{\prime}}{T_{\max }^{\prime}\left(\Gamma_{\mathrm{a}}+\partial \dot{T} / \partial z\right)}$,

where $W_{\max }^{\prime}$ and $T_{\max }^{\prime}$ are the perturbation amplitudes. The results are summarized in Table 2. Because of the uncertainties in the $T^{\prime}$ and $W^{\prime}$ measurements, $\omega$ lies between 0.48 and $0.3310^{-2}$ $\mathrm{s}^{-1}$ with a mean value of $0.3710^{-2} \mathrm{~s}^{-1}$ corresponding to a period of $28.5^{\prime}$. From the dispersion relation (asymptotic approximation)

$\frac{K_{x}}{K_{z}}=\left(\frac{N_{2}}{\omega^{2}}-1\right)^{1 / 2}$,

where $N=2 \cdot 10^{-2} \mathrm{~s}^{-1}$ is the Brunt-Väisälä frequency, the ratio $K_{z} / K_{x}$ is found to be about 6 . The downward phase velocity $W_{\odot}$ can be estimated directly:

Table 2. Characteristics of the wave motion

\begin{tabular}{llll}
\hline $\begin{array}{l}\text { Altitude } \\
(\mathrm{km})\end{array}$ & $\begin{array}{l}\text { Frequency } \\
\omega\left(\mathrm{s}^{-1}\right)\end{array}$ & $\begin{array}{l}\text { Amplitude of the } \\
\text { vertical velocity } \\
\left(\mathrm{m} \mathrm{s}^{-1}\right)\end{array}$ & $\begin{array}{l}\text { Vertical } \\
\text { momentum } \\
\text { flux }\left(\mathrm{N} \mathrm{m}^{-2}\right)\end{array}$ \\
\hline 25 & $0.30 \cdot 10^{-3}$ & 0.42 & $1.8 \cdot 10^{-2}$ \\
24.4 & $0.44 \cdot 10^{-3}$ & 0.44 & $1.9 \cdot 10^{-2}$ \\
23.6 & $0.48 \cdot 10^{-3}$ & 0.49 & $2.4 \cdot 10^{-2}$ \\
22 & & 0.21 & \\
20 & $0.35 \cdot 10^{-3}$ & 0.35 & $3.2 \cdot 10^{-2}$ \\
19 & $0.37 \cdot 10^{-3}$ & 0.33 & $3.1 \cdot 10^{-2}$ \\
18.2 & $0.32 \cdot 10^{-3}$ & 0.33 & $4.2 \cdot 10^{-2}$ \\
17.2 & $0.32 \cdot 10^{-3}$ & 0.40 & $6.8 \cdot 10^{-2}$ \\
16.6 & $0.35 \cdot 10^{-3}$ & 0.45 & $9.0 \cdot 10^{-2}$ \\
15.5 & $0.31 \cdot 10^{-3}$ & 0.48 & $3.5 \cdot 10^{-2}$ \\
\hline
\end{tabular}


$W_{\oplus}=\frac{\omega \lambda_{m}}{2 \pi}$

and is $W_{\phi}=0.9 \mathrm{~m} \mathrm{~s}^{-1}$, a value much smaller than the vertical velocity $W_{p}$. We can conclude that the balloon is making a nearly vertical sounding of the wave perturbations.

The actual vertical wavelength can be calculated from

$\lambda_{z}=\frac{\lambda_{m}}{1-W_{\Phi} / W_{P}}=1.9 \mathrm{~km}$.

Thus the horizontal wavelength $\lambda_{x}$ is about 11.5 $\mathrm{km}$. For a gravity wave, the ratio of the horizontal to the vertical amplitude velocity perturbations is (eqs. (13), (14)) $K_{z} / K_{x}$. This leads to a small amplitude of the horizontal velocity $\left(\simeq 2.4 \mathrm{~m} \mathrm{~s}^{-1}\right)$ and explains why it has not been possible to extract this parameter from our measurement below a large rising balloon.

\subsection{Wave momentum flux}

Gravity waves are a common occurrence in the lee of mountains. The horizontal wavelength is of the order of $10-20 \mathrm{~km}$ and the system is two dimensional and nearly stationary with respect to the ground. Such a configuration appears possible in the case of our observation since tropospheric wave systems are often observed with SW-NE winds in this region. All the qualitative and quantitative results reported here are quite consistent with the general characteristics of a lee wave system. Gravity waves are capable of exchanging momentum and the vertical flux of horizontal momentum is given by

$K=\overline{\rho U^{\prime} W^{\prime}}$,

where the bar denotes horizontal average distance. We have explained in subsection 5.1 why it was not possible to estimate $U^{\prime}$ and consequently we cannot define the direction of the momentum flux. However, following Massman (1982) we can estimate the intensity of $K$ as:

$|K|=\rho \frac{N}{\omega} \overline{W^{\prime 2}}$,

where the average is approximated by a vertical average over one wavelength. In Table 2 we have summarized the values of $|K|$ calculated from (25).

\section{Discussion and conclusion}

One of the objectives of the 1980 test flight of the helisonde was to investigate the ability of the instrument to detect gravity waves in a broad altitude range, especially in the middle stratosphere where in situ measurements are sparse. Analysis of the pressure, temperature and relative velocity data has shown that the detection of small-amplitude waves is possible up to $27 \mathrm{~km}$ perturbation. In the troposphere, however, some limitations arise from the presence of a high mean temperature gradient which masks the temperature fluctuations. With the actual device, it has not been possible to extract the horizontal velocity perturbation because, during the sounding, a large volume balloon cannot be assumed to be a perfect wind sensor. The next step will be to use two instrumented gondolas below the balloon in order to suppress this spurious effect. Then it will become possible to measure the direction of the momentum flux.

Despite these limitations we have observed a wave motion with a period of about $30^{\prime}$ above a jet stream. The vertical and horizontal wavelengths were $1.9 \mathrm{~km}$ and $11.5 \mathrm{~km}$, respectively, and there was a downward phase velocity. These characteristics are quite consistent with the presence of a two-dimensional wave in the lee of the Pyrenean mountains. While these waves have generally been assumed to be trapped in the troposphere (Lilly and Kennedy, 1973), we have provided evidence that there is a significant momentum flux in the stratosphere. The values of $K$ that we obtain around $17 \mathrm{~km}$ are, however, of the same order of magnitude as those reported in Fig. 14 of the Lilly and Kennedy paper.

Massman (1981) investigated gravity waves in the lower stratosphere and found waves with a period around $30 \mathrm{~min}$ and a vertical velocity of 0.3 $\mathrm{m} \mathrm{s} \mathbf{s}^{-1}$ which is quite comparable to the values observed by the helisonde. It is difficult to relate the two types of observations but this frequent occurrence of short-period gravity waves in the stratosphere encourages us to further develop our instrumentation and to fully investigate the wave interaction between the troposphere and the stratosphere. 


\section{Appendix}

\section{Time response of the microbead thermistor}

The time response of the microbead thermistor can be written

$t=\frac{0.66 \rho C r 2}{\lambda(2+N u)}$,

where

$\rho$ : density of the thermistor $\left(8.9 \cdot 10^{3} \mathrm{~kg} \mathrm{~m}^{-3}\right)$,

$C$ : specific heat of the thermistor $\left(3.9 \cdot 10^{2} \mathrm{~J} \mathrm{~kg}^{-1}\right.$ $\mathbf{K}^{-1}$,

$\lambda$ : thermic conductivity of air $\left(1.95 \cdot 10^{-2} \mathrm{~W} \mathrm{~m}^{-2}\right.$ $\mathrm{K}^{-1}$ ),

$r$ r radius of the microbead $\left(r=10^{-4} \mathrm{~m}\right)$. In eq. (Al), Nu is the Nusselt number

$\mathrm{Nu}=0.66 \mathrm{PR}^{1 / 3} \mathrm{Re}^{1 / 2}$,

where $\mathbf{P r}$ is the Prandlt number

$\operatorname{Pr}=\frac{\mu C_{p}}{\lambda}$. $\mu$ : dynamic viscosity $\left(1.42 \cdot 10^{-9} \mathrm{~kg} \mathrm{~m}^{-1} \mathrm{~s}^{-1}\right)$,

$C_{p}$ : specific heat of air at constant pressure, and $\mathrm{Re}$ the Reynold's number:

$\operatorname{Re}=\frac{2 r \rho^{\prime} U}{\mu}$

where

$\rho^{\prime}$ : density of air,

$U^{\prime}$ : relative velocity of the air around the thermistor.

In a wind of velocity $U=5 \mathrm{~ms}^{-1}$, $\tau$ varies between $4.7 \mathrm{~s}$ at the ground level to $19 \mathrm{~s}$ around 25 $\mathrm{mb}$. This gives a lag distance on the temperature profile ranging from $26 \mathrm{~m}$ to $100 \mathrm{~m}$. The effect introduces a bias phase lag $\delta \Phi$ between the temperature and the vertical velocity profiles. In Table 1 , the phase difference $\Delta \Phi_{r^{\prime} w}$, is corrected by the factor $\delta \Phi^{\circ}=360 \times W \tau / \lambda$.

\section{REFERENCES}

Barat, J. 1982. Some characteristics of clear-air turbulence in the middle stratosphere. J. Almos. Sci. IJ, 2553-2564.

Barat, J. and Genie, J. C. 1982. A new tool for the three-dimensional sounding of the atmosphere: the helisonde. J. Appl. Meteorol. 10, 1497-1505.

Bertin, F., Testud, J., Kersley, L. and Rees, P. R. 1977. The meteorological jet stream as a source of medium. scale gravity waves in the thermosphere: an experimental study. J. Atmos. Terr. Phys. 40, 11611183.

Chanin. M. L. and Hauchecorne, A. 1981. Lidar observations of gravity and tidal waves in the stratosphere and mesosphere. J. Geophys. Res. 20, 9715-9721.

Holton, J. R. 1982. The rôle of gravity wave induced dray and diffusion in the momentum budget of the mesosphere. J. Atmos. Sci. 39, 791-799.

Lalas, D. P. and Einaudi, F. 1980. Tropospheric gravity waves: their detection by an influence of ravinsonde balloon data. $Q$.J. R. Meteorol. Soc. J06, 855-864.
Lily, D. K. and Kennedy, P. J. 1973. Observation of a stationary mountain wave and its associated momentum flux and energy dissipation. J. Atmos. Sci. 30. 1135-1152.

Lindzen, R. S. 1981. Turbulence and stress due to gravity wave and tidal breakdown. J. Geophys. Res. 86. 9707-9714.

Massman, W. J. 1981. An investigation of gravity waves on a global scale using twerle data. J. Geophys. Res. 86, 4072-4082.

Matsuno, T. 1982. A quasi-one-dimensional model of the middle atmosphere circulation interacting with internal gravity wave. J. Meteorol. Soc. Japan, Special Issue in commemoration of the Centennial of the Meteorological Society of Japan, 60, 215-226.

Rüster, R., Rö̈tger, J. and Woodman, R. F. 1978. Radar measurements of waves in the lower stratosphere. Geophys. Res. Lett. 5, 555-558.

Uccellini, L. W. 1975. A case study of apparent gravity wave initiation of severe convective storms. Mon. Wea. Rev. 103, 497-513. 